\title{
Tumour necrosis factor- $\alpha$ gene expression by alveolar macrophages in human lung allograft recipient with recurrence of sarcoidosis
}

\author{
S. Martel, P.C. Carré, G. Carrera, B. Pipy, P.J. Léophonte \\ and the Toulouse Lung Transplantation Group*
}

Tumour necrosis factor- $\alpha$ gene expression by alveolar macrophages in human lung allograft recipient with recurrence of sarcoidosis. S. Martel, P.C. Carré, G. Carrera, B. Pipy, P.J. Léophonte and the Toulouse Lung Transplantation Group. @ERS Journals Ltd 1996.

ABSTRACT: Recurrence of sarcoidosis in lung allografts is an interesting model to study the pathogenesis of this disease. We report a case of sarcoidosis recurrence in a single lung allograft recipient 2 years after transplantation.

The expression of tumour necrosis factor- $\alpha(\mathrm{TNF}-\alpha)$ gene by alveolar macrophages was monitored.

The TNF- $\alpha$ gene was not expressed at the time of recurrence of sarcoidosis, but only later when prominent granulomas were observed.

Eur Respir J., 1996, 9, 1087-1089.
Service de Pneumologie et Allergologie et INSERM CJF 91-07, CHU Rangueil, Toulouse, France.

Correspondence: P.C. Carré, Clinic of Respiratory Diseases, 77 Rue de Verdun 11000 Carcassonne, France

Keywords: Lung, sarcoidosis, tumour necrosis factor- $\alpha$, transplantation

Received: November 111994

Accepted after revision November 231995

This work was supported by the Bourse de Recherche Synthelabo "Lung Cell Biology".
End-stage fibrosis due to sarcoidosis is an unusual, but previously reported, indication for lung transplantation [1]. Recurrence of sarcoidosis has been demonstrated in renal [2] and cardiac [3] transplantation, and two recent studies have noted it in lung transplantation $[4,5]$. Such cases offer a unique occasion to monitor the development of sarcoid granulomas in the lung and of local biological abnormalities potentially relevant to the pathogenesis of sarcoidosis. Although mechanisms regulating this pathogenesis remain poorly understood, a number of mediators have been involved, such as proteases, oxygen metabolites, arachidonic acid metabolites and cytokines [6]. Among these cytokines, tumour necrosis factor-alpha $(\mathrm{TNF}-\alpha)$ is likely to play a role. Alveolar macrophages from patients with active sarcoidosis have an increased in vitro secretion of TNF- $\alpha$ and an increased TNF- $\alpha$ mesenger ribonucleic acid (mRNA) expression when compared to healthy subjects [7-9]. A similar increase has also been observed in other granulomatous diseases [10]. TNF- $\alpha$ has been shown to stimulate T-lymphocyte proliferation, expression of class II histocompatibility antigens and release of cytokines, such as interleukin-1 and interleukin-6 (IL-1 and IL-6) [11]. As such, it has been involved in the pathogenesis of sarcoidosis and also in acute rejection in experimental models of lung transplantation [12].

We report a case of recurrence of sarcoidosis in the allograft 2 yrs after a single lung transplantation. Sequential

\footnotetext{
*The members of the Toulouse Lung Transplantation Group are as follows. Chest Diseases: P. Léophonte, A. Didier, Ph. Carré; Surgery: G. Fournial, M. Dahan, J. Berjaud; Anesthesiology: P. Rouge, B. Meusberger; Radiology: H. Rousseau, F. Joffre; Respiratory Physiology: P. Besombes, C. Puel-M'Rini, J. Pecoul; Nephrology and MultiOrgan Transplant Center: D. Durand, J.J. Lloveras, L. Rostaing.
}

monitoring allowed us to demonstrate a lack of increase in the expression of TNF- $\alpha$ gene by alveolar macrophages at the time of recurrence. In contrast, we observed an increased expression occurring later in the disease process when granulomas were associated with acute rejection.

\section{Case report}

In November 1990, a 25 year old man underwent a right single lung transplantation for end-stage lung fibrosis attributed to stage IV sarcoidosis. Histological diagnosis of sarcoidosis was obtained on a prescalenic node biopsy performed 2 yrs previously. The explanted lung demonstrated extensive fibrosis with honeycombing but no active granulomatous disease. Post-transplantation immunosuppression included cyclosporin, prednisone and azathioprine. In 1991, no complications occurred. Nine months after surgery, the forced expiratory volume in one second (FEV1) was $3 \mathrm{~L}$ (FEV1/forced vital capacity (FVC) $88 \%$ ). In January 1992, a clinical rejection episode occurred, not confirmed by biopsies. The patient was treated with a 3 day steroid pulse (methylprednisolone $1 \mathrm{~g} \cdot \mathrm{day}^{-1}$ ) followed by an increase in prednisone dosage (prednisone $50 \mathrm{mg} \cdot \mathrm{day}^{-1}$ tapering to $15 \mathrm{mg} \cdot \mathrm{day}^{-1}$ in 2 weeks). In March 1992, the patient developed a febrile bronchitis due to myxovirus influenzae. Twenty two months after lung transplantation (September 1992), a grade 2 rejection episode occurred. The patient received the same steroid regimen as had been prescribed in January 1992.

In November 1992, transbronchial biopsies (TBB) demonstrated a few noncaseating granulomas consistent with recurrence of sarcoidosis. This finding was associated with a $0.5 \mathrm{~L}$ drop in FEV1 (FEV1/FVC 89\%). At this time, 
acid-fast stains were negative and no fungal elements or cysts were identified. Chest radiographic image was normal but computed tomographic (CT) scan demonstrated discrete ground-glass opacities, without significant mediastinal nodal enlargement. Serum angiotensin converting enzyme was slightly elevated to 28.4 units (normal range 11-23 units). Prednisone was increased from 15 to 40 $\mathrm{mg} \cdot$ day $^{-1}$. One month later (December 1992), granulomas were no longer observed in TBB and the prednisone dosage was gradually reduced to $20 \mathrm{mg} \cdot \mathrm{day}^{-1}$ in the following month.

In January 1993, prominent granulomas associated with a grade 1 rejection were observed in TBB and no associated infectious process could be identified. The patient was treated with a steroid pulse and then remained on prednisone, $40 \mathrm{mg} \cdot \mathrm{day}^{-1}$. In February 1993, a grade $1 \mathrm{re}-$ jection was still observed, whilst there was no more granulomas. At this time, FEV1 was $1.45 \mathrm{~L}$ (FEV1/FVC $66 \%$ ). From February to September 1993, prednisone was gradually tapered to $30 \mathrm{mg} \cdot \mathrm{day}^{-1}$; respiratory functional status remained stable in this period. In November 1993, a further decrease in FEV1 led to transbronchial biopsies and since no acute rejection, granulomas or infectious process could be identified, this functional deterioration was attributed to bronchiolitis obliterans syndrome (BOS). Two subsequent transient increases of the prednisone dosage have permitted the respiratory functional status to be stabilized. Today, the patient is still alive 54 months after transplantation, with a FEV1 of $0.85 \mathrm{~L}$ (BOS stage 3a).

Measurements of TNF- $\alpha$ and $\beta$-actin gene expression by alveolar macrophages were made in seven bronchoalveolar lavages (BAL) from this patient, using techniques described previously $[10,13]$. The first BAL was performed in November 1991, when no complications had yet occurred. The second BAL was performed in

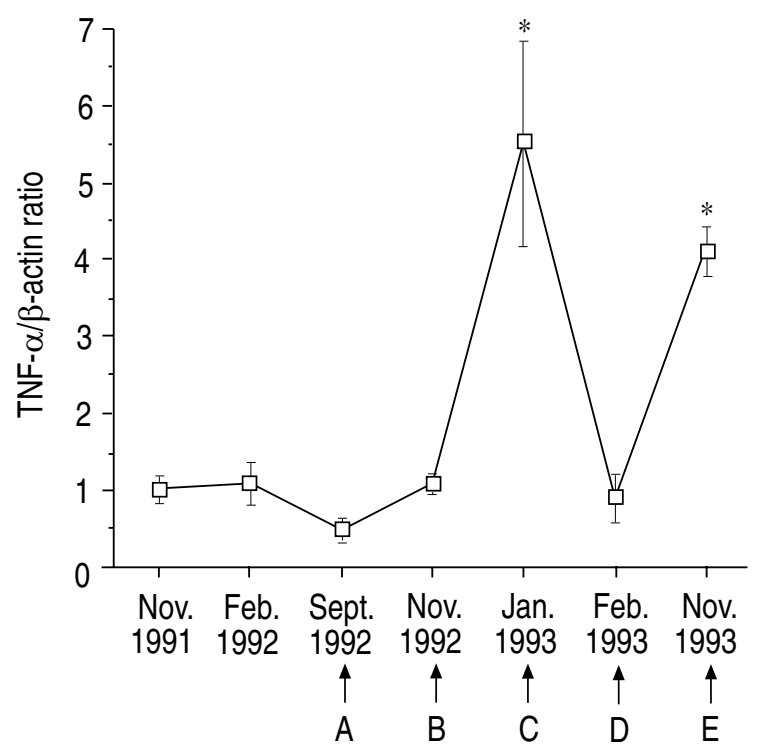

Fig. 1. - Follow-up of alveolar macrophages TNF- $\alpha / \beta$-actin expression (ratio \pm SEM) over a 2 year period. A: acute rejection grade 2 ; B: recurrence of sarcoidosis (granulomas); $\mathrm{C}$ : acute rejection grade 1 and granulomas; D: acute rejection grade 1; E: bronchiolitis obliterans syndrome; TNF- $\alpha$ : tumour necrosis factor- $\alpha$. *: these two values are not significantly different from each other but they are significantly higher $(\mathrm{p}<0.05)$ than the other five values.
February 1992, 1 month after the clinical rejection episode. The subsequent lavages were carried out in September 1992 (grade 2 rejection), November 1992 (granulomas), January 1993 (grade 1 rejection and granulomas), February 1993 (grade 1 rejection) and November 1993 (BOS). As shown in figure 1, formation of granulomas in November 1992 was not associated with an increased expression of the TNF- $\alpha$ gene by alveolar macrophages, but TNF- $\alpha$ gene expression increased later in January 1993 when granulomas were associated with a grade 1 rejection. The gene expression returned to baseline after increase of the steroid dosage and disappearance of the granulomas. At the time of BOS, TNF- $\alpha$ gene expression subsequently peaked. Values in January 1993 and November 1993 are not significantly different from each other but are significantly higher $(\mathrm{p}<0.05$, unpaired t-test $)$ than the five other values.

\section{Discussion}

The incidence of recurrence of sarcoidosis in a lung allograft is not known but is likely to be frequent. Indeed, in the two other reports published so far on this topic, sarcoid granulomas developed in the allograft of five of the seven patients transplanted for end-stage pulmonary sarcoidosis [4, 5]. This phenomenon is an interesting model to study the pathogenesis of sarcoidosis. In the follow-up of this patient, we observed an increase in TNF$\alpha$ gene expression by alveolar macrophages; this overexpression was not observed when granulomas were first found in November 1992 but later, in January 1993, when granulomas were associated with a grade 1 acute rejection. Although quantification of granulomas on transbronchial biopsies remains difficult, it is notable that granulomas were prominent in January 1993 but not in November 1992. We can, therefore, hypothesize that TNF- $\alpha$ is not implicated in the early events of formation of granulomas in lung sarcoidosis but rather plays a role in perpetuating and increasing the granulomatous process.

Another potential explanation would be that there is a synergia for TNF- $\alpha$ gene expression when sarcoidosis and rejection are associated. Indeed, an overexpression of TNF- $\alpha$ gene has been demonstrated not only in sarcoidosis [10] but also in experimental models of lung allograft rejection [12]. Against this hypothesis, there was no increase of TNF- $\alpha$ gene expression by alveolar macrophages at the time of a grade 2 rejection episode in September 1992. This is apparently in contrast with observations made in rejection of human liver and renal allografts, where in situ expression of TNF- $\alpha$ gene using in situ hybridization was shown to be increased [14, 15]. However, in rejection of human lung allografts, only one report showed an increase in spontaneous in vitro TNF$\alpha$ production by alveolar macrophages; two other studies did not observe this phenomenon and even showed a decrease in stimulated TNF- $\alpha$ production by alveolar macrophages when compared to healthy lung recipients [16-18].

Finally, TNF- $\alpha$ gene expression by alveolar macrophages subsequently peaked when our patient developed BOS. Little is known about the role of cytokines in the patho- 
genesis of obliterative bronchiolitis. Fibrogenic growth factors seem to be implicated, since HERTz et al. [19] demonstrated an increased concentration of platelet-derived growth factor in lavage fluid from lung allograft recipients with obliterative bronchiolitis. As we have shown [20], gene expression of inflammatory cytokines, such as interleukin-8 (IL-8) is elevated in the course of other small airway diseases, such as bronchiolitis obliterans with organizing pneumonia. No study has yet investigated the role of TNF- $\alpha$ in the pathogenesis of obliterative bronchiolitis. However, this cytokine has been shown to be involved in fibroproliferative disorders [21].

This case report shows that the follow-up of the behaviour of alveolar cells in lung transplant recipients can be relevant to the study of the pathogenesis of complications such as BOS and also, in the case of transplantation for end-stage pulmonary sarcoidosis, to the study of the potential role of these cells and cytokines in the pathogenesis of this disease, since it seems to recur quite often. It also provides new information about the potential role of tumour necrosis factor- $\alpha$ in the orchestration of lung inflammation in the transplanted lung and in the pathogenesis of sarcoid granulomas.

Acknowledgements: The authors are indebted to K.S. Thach for having performed the bronchoalveolar lavage. They thank P. Galan, N. Harribey and C. Noto for their valuable technical assistance.

\section{References}

1. Scott J, Higenbottam T. Transplantation of the lungs and heart and lung for patients with severe pulmonary complications from sarcoidosis. Sarcoidosis 1990; 7 : 9-11.

2. Beaufils H, Gompel A, Gubler MC, Lucskom M, Creudon J. Pre- and post-transplant glomerulonephritis in a case of sarcoidosis. Nephron 1983; 35: 124-129.

3. Oni AA, Hershberger RE, Norman DJ, et al. Recurrence of sarcoidosis in a cardiac allograft: control with augmented corticosteroids. J Heart Lung Transplant 1992; 11: 367-369.

4. Johnson BA, Duncan SR, Ohori NP, et al. Recurrence of sarcoidosis in pulmonary allograft recipients. Am Rev Respir Dis 1993; 148: 1373-1377.

5. Øystein B, Foerster A, Boe J, Geiran O. Single lung transplantation as treatment for end-stage pulmonary sarcoidosis: recurrence of sarcoidosis in two different lung allografts in one patient. J Heart Lung Transplant 1994; 13: 24-29.

6. Semenzato G, Agostini C. Immunology of sarcoidosis. In: Interstitial Lung Disease. 2nd edn. Saint-Louis, Mosby Year Book, 1993.

7. Strausz J, Männel DN, Pfeifer S, Borkowski A, Ferlinz
R, Müller-Quernheim J. Spontaneous monokine release by alveolar macrophages in chronic sarcoidosis. Int Arch Allergy Appl Immunol 1991; 96: 68-75.

8. Homolka J, Müller-Quernheim J. Increased interleukin6 production by bronchoalveolar lavage cells in patients with active sarcoidosis. Lung 1993; 171: 173-183.

9. Steffen M, Peterson J, Oldigs M, et al. Increased secretion of tumor necrosis factor- $\alpha$, interleukin-1- $\beta$, and interleukin- 6 by alveolar macrophages from patients with sarcoidosis. J Allergy Clin Immunol 1993; 91: 939-949.

10. Bost TW, Riches DWH, Schumacher B, et al. Alveolar macrophages from patients with beryllium disease and sarcoidosis express increased levels of mRNA for tumor necrosis factor- $\alpha$ and interleukin- 6 but not interleukin13. Am J Respir Cell Mol Biol 1994; 10: 506-513.

11. Semenzato G. Tumor necrosis factor: a cytokine with multiple biological activities. Br J Cancer 1990; 61: 354-361.

12. Saito R, Prehn J, Zuo XJ, et al. The participation of tumor necrosis factor in the pathogenesis of lung allograft rejection in the rat. Transplantation 1993; 55: 967-972.

13. Carré PC, Mortenson RL, King TE Jr, Noble PW, Sable $\mathrm{CL}$, Riches DWH. Increased expression of the interleukin- 8 gene by alveolar macrophages in idiopatic pulmonary fibrosis: a potential mechanism for the recruitment and activation of neutrophils in lung fibrosis. J Clin Invest 1991; 88: 1802-1810.

14. Hoffmann MW, Wonigeit K, Steinhoff G, Herzbeck H, Flad HD, Pichlmayr R. Production of cytokines (TNF$\alpha, \mathrm{IL}-1-\beta)$ and endothelial cell activation in human liver allograft rejection. Transplantation 1993; 55: 329-335.

15. Morel D, Normand E, Lemoine C, et al. Tumor necrosis factor-alpha in human kidney transplant rejection: analysis by in situ hybridization. Transplantation 1993; 55: 773-777.

16. Magnan A, Mege JL, Reynaud M, et al. Monitoring of alveolar macrophage production of tumor necrosis factor- $\alpha$ and intreleukin- 6 in lung transplant recipients. Am J Respir Crit Care Med 1994; 150: 684-689.

17. Rondeau E, Cerrina J, Delarue F, et al. Synthèse de TNF- $\alpha$ par les cellules du lavage bronchiolo-alvéolaire et les cellules mononucléées circulantes chez les transplantés coeur-poumon. Presse Méd 1991; 20: 2007-2008.

18. Lega M, Dauber JH, Urch SE, Banas R, Whiteside TL, Griffith BP. Tumor necrosis factor- $\alpha$ production by alveolar macrophages in heart-lung transplant recipients. $\mathrm{Am}$ Rev Respir Dis 1992; 145: 1036-1041.

19. Hertz MI, Henke CA, Nakhleh RE, et al. Obliterative bronchiolitis after lung transplantation: a fibroproliferative disorder associated with platelet-derived growth factor. Proc Natl Acad Sci USA 1992; 89: 10385-10389.

20. Carré PC, King TE Jr, Mortensen R, Riches DWH. Cryptogenic organizing pneumonia: increased expression of interleukin- 8 and fibronectin genes by alveolar macrophages. Am J Respir Cell Mol Biol 1994; 10: 100-105.

21. Carré Ph, Léophonte P. Cytokines et fibroses pulmonaires. Rev Mal Respir 1993; 10: 193-207. 